\title{
Advanced Treatment of Paper-Making Wastewater Using Catalytic Ozonation with Waste Rice Straw-Derived Activated Carbon-Supported Manganese Oxides as a Novel and Efficient Catalyst
}

\author{
Haifeng Zhuang*, Jianbo Guo, Xiaoting Hong \\ Key Laboratory of Recycling and Eco-treatment of Waste Biomass of Zhejiang Province, \\ Zhejiang University of Science and Technology, Hangzhou, China
}

Received: 31 March 2017

Accepted: 7 Jane 2017

\begin{abstract}
Waste rice straw was converted into activated carbon-supported manganese oxides (MnOx/RSAC) that were first used as a catalyst to improve the performance of ozonation of real paper-making wastewater. The results indicated that catalytic ozonation with the prepared catalyst exhibited a highly efficient performance in advanced treatment of paper-making wastewater, and the corresponding color and COD removal efficiencies were 58.5 and $77.5 \%$, respectively. And the treated wastewater was more biodegradable and less toxic than that in ozone alone. Based on significant inhibition of the radical scavenger and fluorescence test in the catalytic ozonation process, we deduced that the enhancement of catalytic activity was responsible for $\mathrm{MnOx} / \mathrm{RSAC}$ catalyzing ozone to generate more hydroxyl radicals and the possible reaction pathway was proposed. Thus, MnOx/RSAC catalyzing ozonation could serve as a stable, efficient, and economical process with a potential engineering application for treated refractory wastewater, and the results offered new insights for sustainable use of waste rice straw.
\end{abstract}

Keywords: waste rice straw, paper-making wastewater, catalytic ozonation, catalyst, hydroxyl radicals

\section{Introduction}

The massive amount of wastewater generated by the paper-making industry has the potential to cause serious deterioration of the environment and have adverse affects on human health because of its high organic matter, color,

*e-mail: Zhuanggao1984@163.com lignin cellulose, and other toxic pollutants [1-3]. Although most paper-making mills use biological treatment processes for treating their effluents, these processes cannot effectively degrade the pollutants of toxic and refractory wastewater, and it is difficult to achieve the increasingly stringent discharge standards of papermaking wastewater (GB3544-2008, China: color (dilution times): 50; COD: $50 \mathrm{mg} / \mathrm{L}$ )[4]. The biologically pretreated paper-making wastewater with lower biodegradability than the raw wastewater had become a bottleneck for the 
development of the paper-making industry in China [56]. Thus, it is necessary to develop innovative, efficient, and cost-effective technology for advanced treatment of paper-making wastewater.

Ozone is a powerful oxidizing molecule that can react selectively with aromatic and unsaturated moieties for fast decolourization [7-8]; however, the formation of intermediates are usually more resistant to ozone oxidation that would cause the removal of insufficient pollutants without meeting the discharge standard [9]. As an alternative, heterogeneous catalytic ozonation was found to be very effective for eliminating toxic pollutants in wastewater, which overcome the limitations of ozone alone by catalysts to promote the generation of hydroxyl radicals $(\bullet \mathrm{OH})[10]$. The catalysts in this process mainly include metal oxides and their supports. Activated carbon is an especially attractive and promising alternative with high surface area and chemical resistance, which have the dual functions of catalysis and adsorption [11-12]. However, these efficient catalysts have challenges in the technical complexity and high cost of production that limit their full-scale practical application [8]. Meanwhile, the increasing rice production has caused the large production of waste rice straw, which is mostly burned for the purpose of quick disposal, and this cellulose-type material can be converted into activated carbon with advantages of ecofriendly and sustainable development [13]. Moreover, manganese oxide is one of the most reactive catalysts for ozone decomposition in a gas with low cost [14]. Thus, there is a high expectation that the integration of rice straw-derived activated carbon and manganese oxides make catalysts for further enhancing the capacity of ozone oxidation and additional economic benefits. However, to the best of our knowledge, no report about using this type of catalyst to improve the performance of catalytic ozonation for advanced treatment of paper-making wastewater has been published.

In the present study, waste rice straw was recycled and converted into rice straw-derived activated carbon (RSAC), which was supported manganese oxides used as heterogeneous catalyst. The physical and chemical properties of the catalyst have been characterized and its activity of catalytic ozonation of paper-making wastewater was investigated. Meanwhile, the biodegradability and toxicity of treated wastewater was analyzed and the possible reaction mechanism was proposed. Also, the stability of the catalyst has been evaluated. The process was tested to be feasible and a preferable reference to further engineering applications.

\section{Materials and Methods}

\section{Materials}

For this study we used real paper-making wastewater from the pulp and paper mill in Quzhou city in China's Zhejiang Province and that had been treated with the anaerobic-aerobic activated sludge process $(\mathrm{A} / \mathrm{O})$. The characteristics of the wastewater were (in $\mathrm{mg} / \mathrm{L}$ ): COD $210 \pm 20, \mathrm{BOD}_{5} 35 \pm 7$, color $110 \pm 10$ (unit), plus temperature of $30 \pm 5^{\circ} \mathrm{C}$ and $\mathrm{pH}$ of $6.5 \pm 0.5$. Waste rice straws from fivemonth-old rice plants were crushed and sieved to get a particle size ranging from 0.5 to $2.0 \mathrm{~cm}$, and washed with distilled water to remove ash and dried for use. Ozone oxidation was carried out in a model reactor made of cylindrical plexiglas with effective volume of $1.5 \mathrm{~L}$.

\section{Preparing the Catalyst}

The rice straw was impregnated into the $\mathrm{H}_{3} \mathrm{PO}_{4}$ solution $(10 \mathrm{~mol} / \mathrm{L})$ with a mass ratio of $1: 3$ for $12 \mathrm{~h}$ at room temperature [15]. When the supernatant liquid was completely retrieved, the samples were dried at $80^{\circ} \mathrm{C}$, and then the solids were impregnated with $\mathrm{Mn}$ nitrate solution ( $1 \mathrm{~mol} / \mathrm{L}$ ) for $24 \mathrm{~h}$, and subsequently pyrolyzed in a muffle furnace where highly pure $\mathrm{N}_{2}$ was poured in for producing an absence-of-oxygen condition. The furnace temperature was gradually increased at a rate of $5^{\circ} \mathrm{C} / \mathrm{min}$, and the final temperature of $550^{\circ} \mathrm{C}$ was maintained for $4 \mathrm{~h}$. After carbonization, the products were washed by $\mathrm{HCl}(36 \%)$ to remove inorganic impurity, and then thoroughly washed with Milli-Q water until $\mathrm{pH}$ of rinsed water became constant and dried, and denoted as the MnOx/RSAC.

\section{Experimental Procedures}

The real paper-making wastewater and $1 \mathrm{~g} / \mathrm{L}$ of catalyst were added into the reactor, which was shaken for $48 \mathrm{~h}$ to ensure adsorption equilibrium, and the equilibrium concentration was measured. And then the degradation reaction was initialed by a continuous input of ozone gas, which was generated from pure oxygen using a corona discharge ozone generator (DHX-I, Harbin Jiujiu Electrochemistry Technology Co., Ltd., China) and delivered into a reactor through a sinteredglass diffuser at the bottom of the reactor. The flow rate of ozone gas was $450 \mathrm{ml} / \mathrm{min}$ and ozone gas concentration was $10 \mathrm{mg} / \mathrm{L}$, and the off-gas was quenched by $5 \%$ of KI solution. Additionally, the added concentration of tertbutanol (TBA) as a radical scavenger in the ozonation process was $80 \mathrm{mg} / \mathrm{L}$. After residual ozone was removed by being pumped into an amount of $\mathrm{N}_{2}$ in the solution, samples were withdrawn at pre-selected time intervals followed by filtering with $0.45 \mu \mathrm{m}$ filter paper and further analyzed.

\section{Analytical Methods}

BET surface area and pore size distribution were determined using $\mathrm{N}_{2}$ adsorption-desorption experiments (Micromeritics ASAP 2020). X-ray fluorescence spectra (XRF) (Axios-pw4400, Holland) were applied to analyze the chemical elements composition (excluding $\mathrm{C}, \mathrm{H}$, and $\mathrm{O})$. The concentration of the dissolved metal ions in the catalytic ozonation process was analyzed by ICP-AES (Optima 5300DU, Perkin Elmer Inc). The morphology and structure of the prepared catalyst was examined with 
scanning electron microscopy (SEM, Helios Nanolab 600i Scanning Electron Microscope). The crystal structure was analyzed by a powder x-ray diffractometer (XRD, RigakuD/max-2000) with monochromatic $\mathrm{Cu} \mathrm{Ka}$ radiation $(45 \mathrm{kV}, 50 \mathrm{~mA})$. The generation of $\bullet \mathrm{OH}$ was monitored by mean of terephthalic acid fluorescent probe method on an RF-6500 fluorescence spectrometer. The Langmuir and Freundlich model can be expressed mathematically as: $\frac{x}{m}=\frac{Q_{0} b q_{e}}{1+b q_{e}} ; q=\frac{x}{m}=K_{f} C_{e}^{1 / n}$, respectively $\left(25^{\circ} \mathrm{C}\right)$, where $x / m$ is the amount adsorbed at equilibrium $(\mathrm{mg} / \mathrm{g}$ ), $Q_{0}$ is the maximum adsorption capacity $(\mathrm{mg} / \mathrm{g}), q_{e}$ is the equilibrium concentration $(\mathrm{mg} / \mathrm{L}), b$ is the Langmuir constant $(\mathrm{L} / \mathrm{mg})$, and $\mathrm{K}_{\mathrm{f}}$ and $n$ are Freundlich constants. $\mathrm{COD}$, biochemical oxygen demand $\left(\mathrm{BOD}_{5}\right)$, and color were measured according to Standard Methods [16]. The acute toxicity of the wastewater was assessed by the Daphnia magna test following the National Standards of China (Water Quality-Determination of the Acute Toxicity of a Substance to Daphnia, GB/T13266-91). All the experiments were repeated three times, and the results are the average of at least three measurements with an accuracy of $\pm 5 \%$.

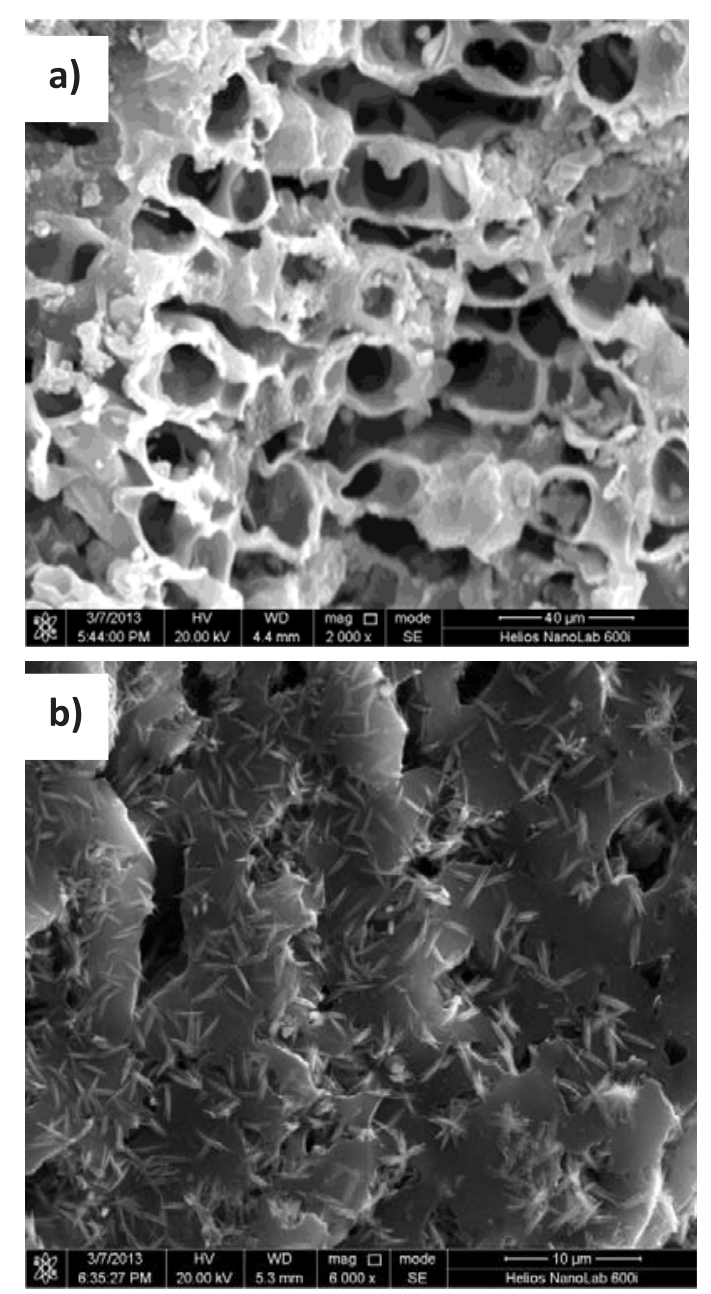

Fig. 1. SEM images of the catalysts: a) RSAC and b) MnOx/ RSAC.
Table 1. Physicochemical properties of the catalysts.

\begin{tabular}{|c|c|c|}
\hline Parameters & RSAC & MnOx /RSAC \\
\hline $\mathrm{S}_{\text {BET }}\left(\mathrm{m}^{2} \mathrm{~g}^{-1}\right)$ & 917.6 & 901.1 \\
\hline $\mathrm{V}_{\text {meso(macro) }}\left(\mathrm{cm}^{3} \mathrm{~g}^{-1}\right)$ & 0.365 & 0.331 \\
\hline $\mathrm{V}_{\text {micro }}\left(\mathrm{cm}^{3} \mathrm{~g}^{-1}\right)$ & 0.226 & 0.202 \\
\hline Pore size $(\mathrm{nm})$ & 4.351 & 3.752 \\
\hline $\mathrm{Mn}(\mathrm{wt} \%)$ & 0.13 & 11.75 \\
\hline $\mathrm{C}(\mathrm{wt} \%)$ & 47.85 & 52.79 \\
\hline $\mathrm{H}(\mathrm{wt} \%)$ & 5.37 & 4.95 \\
\hline $\mathrm{N}(\mathrm{wt} \%)$ & 1.12 & 1.29 \\
\hline
\end{tabular}

\section{Results and Discussion}

\section{Characteristics of the Prepared Catalyst}

As shown in Table 1, RSAC exhibited high specific surface area with $917.6 \mathrm{~m}^{2} \mathrm{~g}^{-1}$, and the microspores and meso(macro) pores volumes as well as the average pore size all represented its well-developed mesoporous character, which may be attributed to the activation and pore-forming effects of $\mathrm{H}_{3} \mathrm{PO}_{4}$ on the hemicelluloses, cellulose, and lignin components of rice straw [15]. The introduction of $\mathrm{MnOx}(11.75 \%$, XRF) did not significantly change the distribution of the pore diameter and the specific surface area, and main organic elementals were $\mathrm{C}, \mathrm{H}$, and $\mathrm{N}$, which was accorded the material nature of rice straw. Meanwhile, SEM images revealed that the RSAC surface was very uneven, rough, and porous, and $\mathrm{MnOx}$ with amorphous cluster were uniformly attached to RSAC surface and embedded in the porous structure. Moreover, XRD patterns of RSAC showed a wide peak at $23.5^{\circ}$ and corresponding to the graphite carbon structure that was similar to that of activated carbon (Fig. 2). $\mathrm{MnOx} / \mathrm{RSAC}$ exhibited the similar characteristic peaks of the corresponding support, which was in line with Mn oxides uniformly immobilized in RSAC.

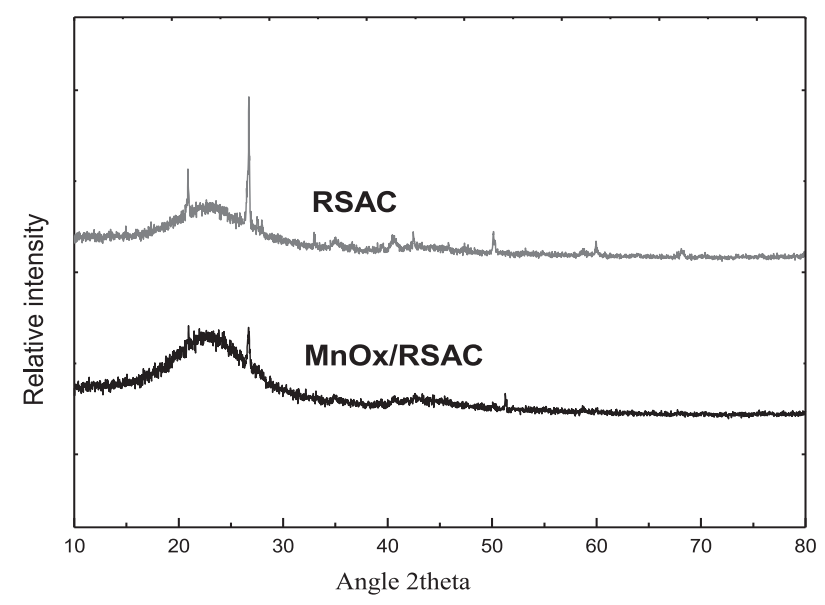

Fig. 2. XRD pattern of the catalysts. 
Table 2. Adsorption isotherms of the catalysts.

\begin{tabular}{|c|c|c|c|c|c|c|}
\hline \multirow{2}{*}{ Catalysts } & \multicolumn{3}{|c|}{ Langmuir } & \multicolumn{3}{c|}{ Freundlich } \\
\cline { 2 - 7 } & $Q_{0}(\mathrm{mg} / \mathrm{g})$ & $b(\mathrm{~L} / \mathrm{mg})$ & $R^{2}$ & $K_{f}$ & $1 / n$ & $R^{2}$ \\
\hline RSAC & 109.6 & 0.06 & 0.99815 & 23.94498 & 0.30019 & 0.94188 \\
\hline MnOx/RSAC & 102.1 & 0.05 & 0.99426 & 21.43386 & 0.30412 & 0.95201 \\
\hline
\end{tabular}

\section{Adsorption Performance of the Prepared Catalyst}

The adsorption isotherms of the catalyst for the paper-making wastewater were illustrated in Table 2, and the Langmuir model was employed to simulate the adsorption isotherms and fit well with the adsorption isothermal data $\left(r^{2}>0.99\right)$ that showed that the adsorption of pollutants in the paper-making wastewater on the RSAC were a monolayer adsorption. The lower adsorption capacity of $\mathrm{MnOx} / \mathrm{RSAC}$ was attributed to the dilution of $\mathrm{Mn}$ impregnation. Meanwhile, 25.5 and $19.2 \%$ of COD removal were reduced by the adsorption of RSAC and $\mathrm{MnOx} / \mathrm{RSAC}$ in $60 \mathrm{~min}$, further evidencing the good adsorption capacity of the prepared catalyst.

\section{Catalytic Activity of $\mathrm{MnOx} / \mathrm{RSAC}$}

As seen from Figs 3(a-b), only 42.7 and $45.5 \%$ of color and COD were removed in ozone alone, with $60 \mathrm{~min}$ at the raw wastewater $\mathrm{pH}$. The addition of $\mathrm{MnOx} /$ RSAC significantly increased pollutant removal efficiency in ozone, and the corresponding removal efficiency with ozone alone was reached only at $20 \mathrm{~min}$ and the final 58.5 and $77.5 \%$ of Color and COD was removed at $60 \mathrm{~min}$. Treated effluent concentrations were $45.7 \mathrm{U}$ and $47.3 \mathrm{mg} / \mathrm{L}$, respectively, which all met discharge standard paper-making wastewater (GB3544-2008, China). Fig. 3c) indicated ozone concentrations in solution increased rapidly and then reached equilibrium in both process in the first $5 \mathrm{~min}$. The equilibrium ozone concentration in catalytic ozonation was much lower than that in ozone alone, indicating that the addition of the catalyst promoted ozone decomposition and further reduced equilibrium ozone concentration in the solution. The high catalytic activity was closely related to the availability of high specific surface area and the activity of $\mathrm{MnOx}$, which approved more active sites and drove the production of radicals. These results were consistent with those of He et al. [17], who showed that papermaking wastewater pollutants were quickly removed in catalytic ozonation with Fe-supported activated carbon. However, the ozone dosage was 10 times that of this study - especially $\mathrm{MnOx} / \mathrm{RSAC}$, which was prepared from waste rice straw with low cost and efficient advantages and was suitable for further engineering applications.
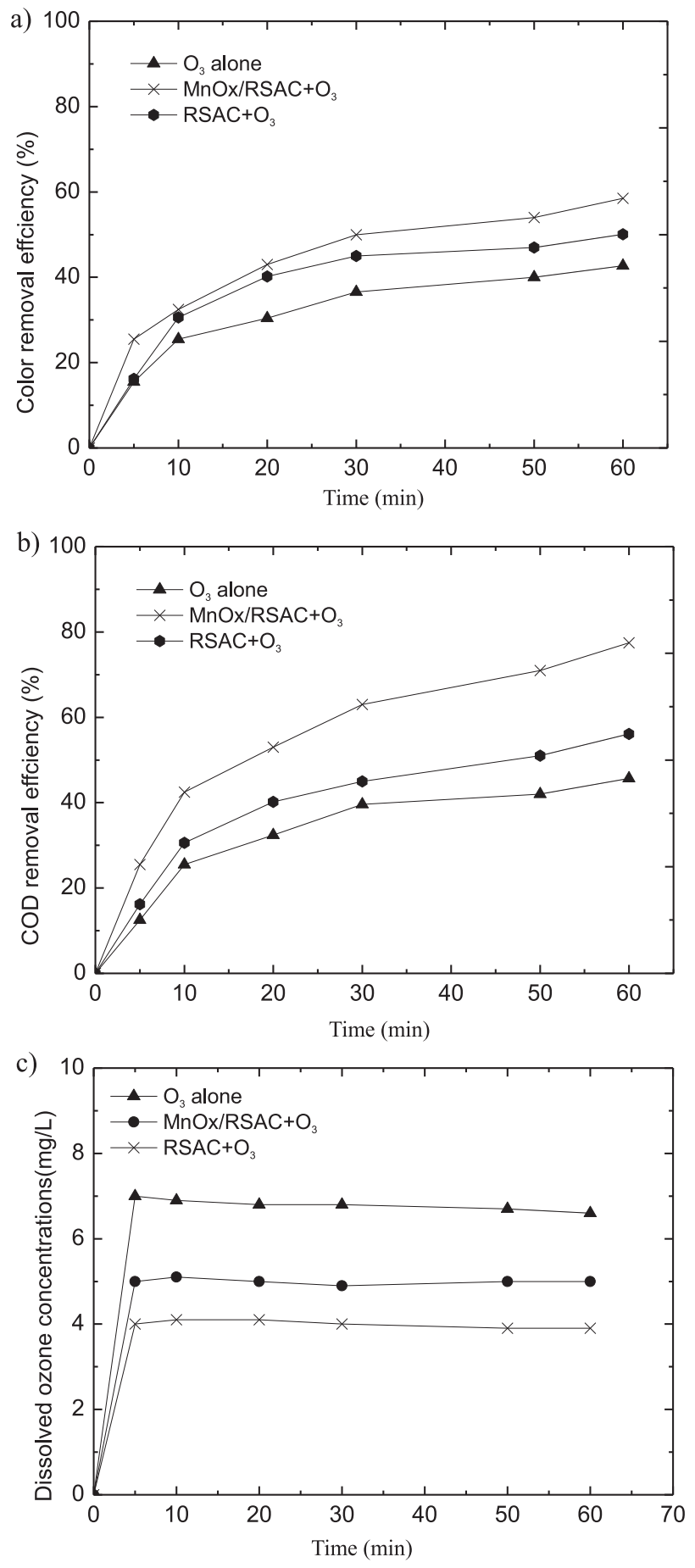

Fig. 3. Effects of catalysts on the performance of pollutant removal in the ozonation process. 


\section{Biodegradability and Toxicity Analysis}

The biologically pretreated paper-making wastewater had low biodegradability with only 0.16 of $\mathrm{BOD}_{5} / \mathrm{COD}$, which was in agreement with bio-refractory wastewater characteristics. With the prolonged ozonation time, the $\mathrm{BOD}_{5} / \mathrm{COD}$ increased gradually from 0.16 to 0.27 (ozone alone), 0.35 (RSAC), and around 0.46 (MnOx/RSAC). A previous report pointed out that the effluent was considered totally biodegradable as $\mathrm{BOD}_{5} / \mathrm{COD}$ higher than 0.4 [1819], and only $\mathrm{MnOx} / \mathrm{RSAC}$ catalyzing ozone achieved this threshold. Meanwhile, acute toxicity was remarkably reduced with heterogeneous ozonation preceding the toxic inhibition rate, which decreased by around $59.1 \%(\mathrm{MnOx} /$ RSAC), 31.8\% (RSAC), and 22.7\% (ozone alone), which indicated that high toxic pollutants were removed and/ or converted into less toxic or even non-toxic substances without secondary environmental pollution. The results offer the feasible option of catalytic ozonation coupled with the biological treatment process for safe and costeffective wastewater treatment.

\section{Possible Reaction Mechanism}

In order to investigate the potential reaction mechanism of catalytic ozonation with $\mathrm{MnOx} / \mathrm{RSAC}$,
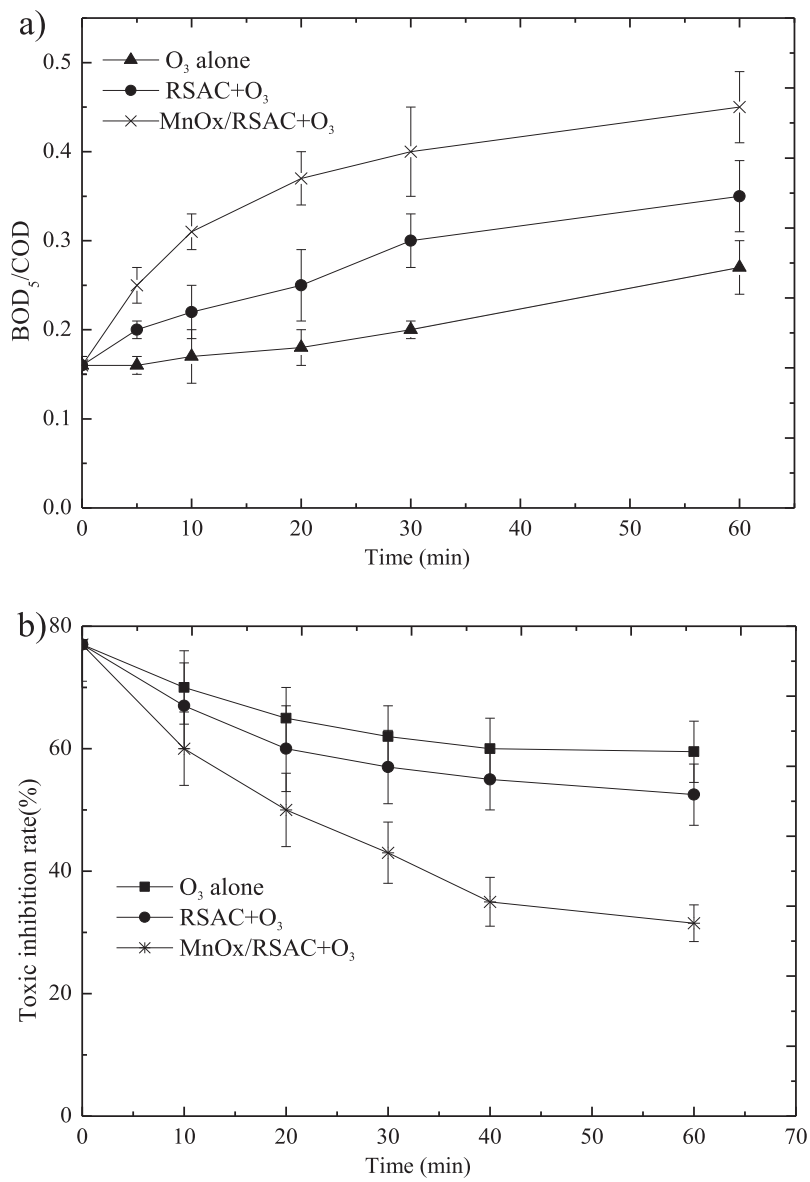

Fig. 4. Changes of biodegradability and acute toxicity in the catalytic ozonation process. experiments were carried out to compare COD removal in the presence or absence of TBA, which was well known with radical scavengers. As shown in Fig. 5a), the addition of TBA affected negatively the activity of the catalyst, and corresponding COD removal efficiency was decreased by $23.4 \%\left(\mathrm{O}_{3}\right.$ alone), $28.6 \%$ (RSAC), and 31.5\% (MnOx/ RSAC), and the largest declined range appeared in the catalytic ozonation system. The results indicated that the main reaction pathways of catalytic ozonation involved the participation of the highly reactive $\cdot \mathrm{OH}$ [8]. Meanwhile, the production quantity of $\bullet \mathrm{OH}$ in a different catalyzing ozonation process was evaluated by a Fluor photometer (Fig. 5b), and the quantity of $\bullet \mathrm{OH}$ was followed by the order of $\mathrm{MnOx} / \mathrm{RSAC}>\mathrm{RSAC}>\mathrm{O}_{3}$ alone, which was consistent with the observed degradation tendency. The following possible reaction pathway was proposed: first, the pollutants and ozone molecules were enriched in $\mathrm{MnOx} / \mathrm{RSAC}$ by efficient adsorption while the pollutants were partly removed or transformed into byproducts by direct ozone oxidation. Then water molecules were adsorbed on the catalyst and dissociated into hydroxyl ion and hydronium, which can promote surface hydroxyl groups while the absorbed ozone would be catalytically decomposed to produce an intermediate $\mathrm{HO}_{2}^{-}$anion by $\mathrm{MnOx}$, further reacting with the ozone molecule to form $\mathrm{O}_{3}^{-}$radical [20]. Finally, the radical decomposed into an oxygen molecule and stronger oxidizer $\bullet \mathrm{OH}$, and then the formed $\cdot \mathrm{OH}$ attacked with the absorbed strength
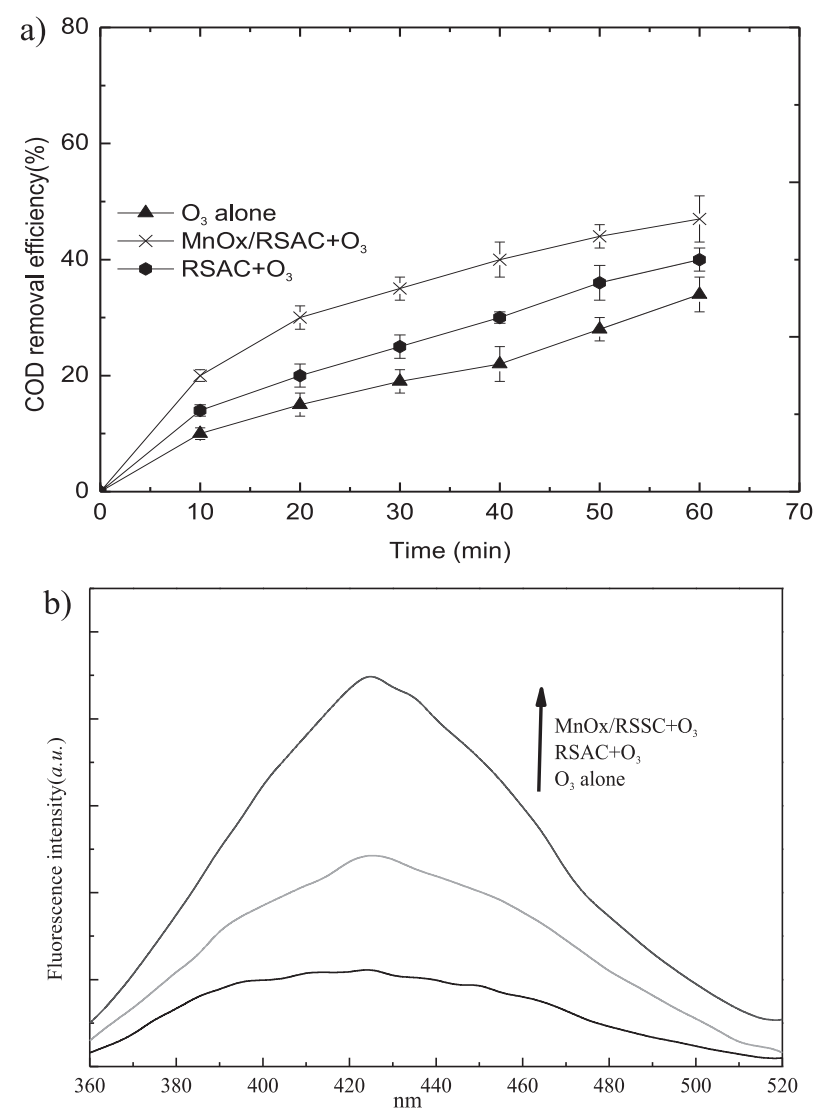

Fig. 5. Mechanism detection: a) effect of radical scavenger on COD removal and b) fluorescence test for radical measurement. 


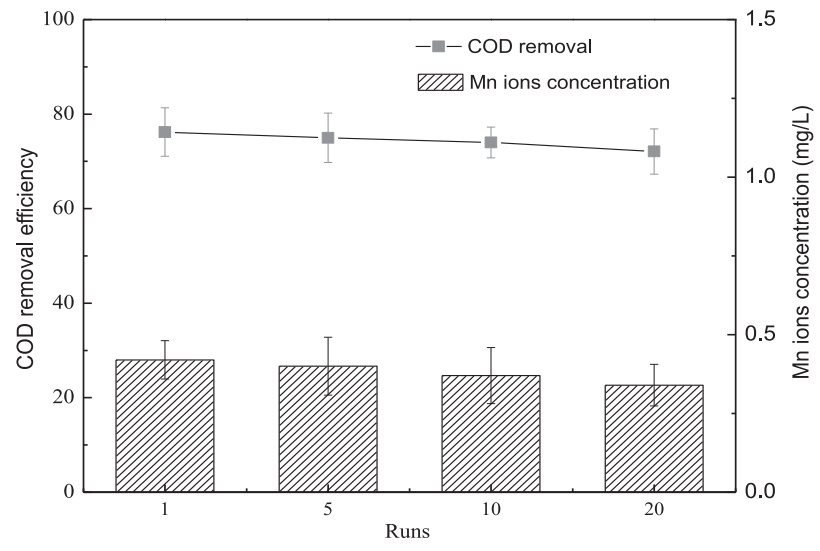

Fig. 6. Catalytic activity of $\mathrm{MnOx} / \mathrm{RSAC}$ in successive runs.

pollutants and degraded into intermediates or were completely eliminated.

\section{Advantages in Application}

Reusability is an important factor of the catalyst for industrial practical applications from the economic viewpoint, thus the stability of $\mathrm{MnOx} / \mathrm{RSAC}$ was investigated in Fig. 6. As compared to the fresh catalyst, no remarkable change was observed on catalytic activity of $\mathrm{MnOx} / \mathrm{RSAC}$, and COD removal efficiency was only decreased by $4.1 \%$ at the $20^{\text {th }}$ reuse, indicating the successive runs of a catalyst with good stability, which was mainly attributed to its developed porous and embedded structure. Meanwhile, the stability of $\mathrm{MnOx} / \mathrm{RSAC}$ was also evaluated by detecting the concentration of $\mathrm{Mn}$ ions along with the successive runs, which was consistent with around $0.5 \mathrm{mg} / \mathrm{L}$ in the cycles of reuse without potential hazards. Thus, the results showed that MnOx/RSAC had efficient and stable catalytic activity for catalytic ozonation of real paper-making wastewater with low cost, eco-friendly, and sustainable advantages, catering to the concept of "using waste to treat waste."

\section{Conclusions}

Waste rice straw was converted into activated carbon-supported $\mathrm{MnOx}$ as a catalyst that significantly improved the performance of pollutant removal in catalytic ozonation of paper-making wastewater, and the 58.5 and $77.5 \%$ of color and COD was removed and the corresponding effluent concentrations met all discharge standard paper-making wastewater. Meanwhile, the biodegradability of the treated wastewater was significantly increased with $\mathrm{BOD}_{5} / \mathrm{COD}$ increasing from 0.16 to 0.46 , and the acute toxicity decreased by $59.1 \%$. Based on the significant inhibition of radical scavenger and fluorescence test in the catalytic ozonation process, we deduced that the enhancement of catalytic activity was attributed to catalyst-promoting ozone decomposition to generate more $\bullet \mathrm{OH}$. Moreover, the catalyst remained a stable catalytic activity at successive runs. Thus, $\mathrm{MnOx} /$ RSAC had efficient and stable catalytic activity for catalytic ozonation of real paper-making wastewater with low cost and sustainable advantages, and was suitable for an engineering application.

\section{Acknowledgements}

This work was supported by the Zhejiang Provincial Natural Science Foundation of China (No. LQ17E080008) and NSFC-Zhejiang Joint Fund for the Integration of Industrialization and Informatization (No. U1609214) and the Public Welfare Technology Application Research Project of Zhejiang Province, China (No. 2016C33108), and the Major Projects for Science and Technology Development of Zhejiang Province (No. $2017 \mathrm{C} 03010$ and 2015C02037).

\section{References}

1. ASHRAFI O., YERUSHALMI L., HAGHIGHAT F., Wastewater treatment in the pulp-and-paper industry: A review of treatment processes and the associated greenhouse gas emission. J. Environ. Manage. 158, 146, 2015.

2. HERMOSILLA D., MERAYO N., GASCO A., BLANCO Á. The application of advanced oxidation technologies to the treatment of effluents from the pulp and paper industry: a review. Environ. Sci. Pollut. Res. 22, 168, 2015.

3. BUYUKKAMACI N., KOKEN E. Economic evaluation of alternative wastewater treatment plant options for pulp and paper industry. Science of the Total Environment. 408, 6070, 2010.

4. LUCAS M.S., PERES J.A., AMOR C., MALDONADO M.I., MALATO S. Tertiary treatment of pulp mill wastewater by solar photo-Fenton. J. Hazard. Mater, 225-226, 173, 2012.

5. RODRIGUES A.C., BOROSKI M., SHIMADA N.S., GARCIA J.C., NOZAKI J. Treatment of paper pulp and paper mill wastewater by coagulation-flocculation followed by heterogeneous photocatalysis. J. Photoch. Photobio. A. 194, 1, 2008.

6. ASGHAR M.N., KHAN S., MUSHTAQ H. Management of treated pulp and paper mill effluent to achieve zero discharge. J. Environ. Manage. 88, 1285, 2008.

7. FARIA P.C.C., ORFAO J.J.M., PEREIRA M.F.R. Activated carbon and ceria catalysts applied to the catalytic ozonation of dyes and textile effluents. Applied Catalysis B: Environmental. 88, 341, 2009.

8. ZHUANG H.F., HAN H.J., HOU B.L., JIA S.Y., ZHAO Q. Heterogeneous catalytic ozonation of biologically pretreated Lurgi coal gasification wastewater using sewage sludge based activated carbon supported manganese and ferric oxides as catalysts. Bioresour Technol. 166, 178, 2014.

9. KASPRZYK-HORDERN B., ZIOLEK M., NAWROCKI J. Catalytic ozonation and methods of enhancing molecular ozone reactions in water treatment. Appl. Catal. B-Environ. 46, 639, 2003.

10. WANG H., QUAN B.X., AN X.Q., YANG Y., TIAN C. Advanced decomposition of coking wastewater in relation to total organic carbon using an electrochemical system. Pol. J. Environ. Stud. 26, 941, 2017. 
11. CHU Y.Y., ZHU M.G., LIU C. Electrochemical treatment of biotreated landfill leachate using a porous carbon nanotubecontaining cathode: Performance, toxicity reduction, and biodegradability enhancement. Environ. Eng. Sci. 32, 445, 2015.

12. HUANG Y., CUI C., ZHANG D. Heterogeneous catalytic ozonation of dibutyl phthalate in aqueous solution in the presence of iron-loaded activated carbon. Chemosphere. 119, 295, 2015.

13. ZANG A.D., GRATHWOHL P. Enhanced immobilization of polycyclic aromatic hydrocarbons in contaminated soil using forest wood-derived biochar and activated carbon under saturated conditions, and the importance of biochar particle size. Pol. J. Environ. Stud. 25, 427, 2016.

14. SUI M.H., XING S.C., SHENG L., HUANG S.H., GUO H.G. Heterogeneous catalytic ozonation of ciprofloxacin in water with carbon nanotube supported manganese oxides as catalyst. J. Hazard. Mater, 227-228, 227, 2012.

15. TORRELLAS S.A., LOVERA R.G., ESCALONA N., SEPULVEDA C., SORELO J.L., GARCIA J. Chemicalactivated carbons from peach stones for the adsorption of emerging contaminants in aqueous solutions. Chem. Eng. J. 279, 788, 2015.
16. APHA, Standard Methods for the Examination of Water and Wastewater, $18^{\text {th }}$ ed. 1992, Washington, DC: American Public Health Association.

17. HE S.M., LI J., XU J., MO L.H. Enhanced removal of COD and color in paper-making wastewater by ozonation catalyzed by $\mathrm{Fe}$ supported on activated carbon. BioResources. 11, 8396, 2016

18. ESPLUGAS S., CINTRERAS S., OLLIS D. Engineering aspects of the integration of chemical and biological oxidation: simple mechanistic models for the oxidation treatment. J. Envir. Eng. 130, 967, 2004.

19. ZHANG H.F., HAN H.J., SHAN S.D. Treatment of British Gas/Lurgi coal gasification wastewater using a novel integration of heterogeneous Fenton oxidation on coal fly ash/sewage sludge carbon composite and anaerobic biological process. Fuel. 178, 155, 2016.

20. IKHLAQ A., BROWN D.R., Kasprzyk-Hordern B. Mechanisms of catalytic ozonation on alumina and zeolites in water: Formation of hydroxyl radicals. Appl. Catal. B: Environ. 123-124, 94, 2012. 